\title{
Probiotic intervention to prevent necrotizing enterocolitis in extremely preterm infants born before 32 weeks of gestation or with a birth weight of less than $1500 \mathrm{~g}$
}

\author{
César Gutiérrez Escárate, M.D. ${ }^{a}$, Luis Bustos Medina, Prof. ${ }^{b}$, \\ Katherine Caniulao Ríos, M.D. ', Carolina Taito Antivil, M.D. ${ }^{c}$, \\ Yessica Gallegos Casanova, M.D. ${ }^{a}$ and Camila Silva Beltrán, M.D. ${ }^{d}$
}

\begin{abstract}
Introduction. There is evidence of the beneficial effects of probiotics to prevent necrotizing enterocolitis in extremely preterm infants. Probiotic prevention has been used since 2015 in the Division of Neonatology of Hospital Hernán Henríquez Aravena, Temuco, Chile.

Objective. To assess the impact of this probiotic on the incidence, severity, surgical treatment requirement, and fatality rate of necrotizing enterocolitis in extremely preterm infants.
\end{abstract}

a. Division of Neonatology, Hospital Dr. Hernán Henríquez Aravena, Temuco, Chile.

b. Department of Public Health, Health Training, Research, and Management (Capacitación, Investigación y Gestión para la Salud, CIGES), Universidad de La Frontera.

c. Division of Pediatrics, Hospital Dr. Hernán Henríquez Aravena, Temuco, Chile.

d. Division of Imaging Studies, Hospital Dr. Hernán Henríquez Aravena, Temuco, Chile.

\section{E-mail address:}

César Gutiérrez

Escarate, M.D.:

cesgutesc@yahoo.com

Funding:

None.

Conflict of interest:

None.

Received: 7-21-2020

Accepted: 12-17-2020

\section{INTRODUCTION}

Necrotizing enterocolitis (NEC) is the most common and severe gastrointestinal emergency in newborn infants, particularly in extremely preterm (EP) infants. Its pathogenesis is complex and multifactorial. Its incidence varies across countries and neonatal centers, reporting $7.5 \%$ rates, ${ }^{1}$ variations, and an upward trend. ${ }^{2}$

Among EP infants at risk for NEC, an abnormal stool colonization and a delayed saprophytic colonization was observed..$^{3,4}$ There is an inverse relationship between the risk for NEC and birth weight and gestational age: less than $10 \%$ of infants that develop NEC are born at term gestation. ${ }^{5}$

Probiotics are live microorganisms that contribute to an adequate gut flora, favor the development of the saprophytic flora, and hurdle the proliferation of pathogenic bacteria. Their use for preventing NEC in EP infants is often mentioned in medical literature, and according to scientific evidence, they are an important tool to reduce severe NEC in preterm infants. ${ }^{6,7}$ The lack of consensus on their routine prophylactic use is related to the type of probiotic used, the required dose, treatment modality, and long-term effects, which has contributed to suggest that further studies should be conducted. ${ }^{8,9}$ The mechanisms of action of probiotics are well known: high affinity to adhere to the intestinal mucosa, improved epithelial barrier function, competitive exclusion of pathogens, inhibition of pathogen adhesion, production of 
antimicrobial substances, and modulation of the host's immune system.

At the end of 2014, a purchase request of Lactobacillus reuteri Protectis (LRP), DSM 17938 strain (BioGaia ${ }^{\circledR}$ ), was sent to the Pharmacy Committee of Hospital Dr. Hernán Henríquez Aravena (HHHA), Temuco, Chile, for its routine use in EP infants. There are no publications in Chile regarding the use of LRP in NEC; this information could therefore be useful for other neonatal centers. The objective of this study was to assess the impact of this probiotic on NEC incidence, severity, surgical treatment requirement, and fatality rate in a group of EP infants, compared to a group who did not receive it.

\section{PATIENTS AND METHODS}

For the sample design, a retrospective cohort of EP infants was used. It included neonates born before 32 weeks of gestation or with a birth weight of less than $1500 \mathrm{~g}$ who started feeding in their first week of life, did not have any malformations, genetic disorders or pathologies preventing their feeding, and were seen at the Division of Neonatology of the HHHA between 2012 and 2017.
The HHHA of Temuco, in the Araucanía Region, Chile, is a regional hospital where patients with complex conditions that cannot be managed in other hospitals of the region are referred to. The Division of Neonatology admits patients born at the hospital or in other centers from the region and, in some cases, from other regions, according to hospitalization availability within the National Health Network.

Our Division promotes feeding breast milk, given its proven beneficial and preventive effects for NEC. Breast milk has bioactive compounds, in addition to probiotics and prebiotics. Colostrum is administered orally to EP infants since the first day of life, intravenous dextrose solution with amino acids, until achieving total parenteral nutrition the following day. The increase of enteral nutrition depends on clinical course and tolerance, so as to achieve the withdrawal of parenteral nutrition as soon as possible. Breast milk is preferably used, as well as preterm formula or a combination of both. Breast milk is fortified when a volume of around $50 \mathrm{ml} / \mathrm{kg} /$ day is reached. This feeding practice has been in use for more than 10 years.

Patients were divided into two groups according to the year of discharge: the control

TABLE 1. Bell's staging criteria for necrotizing enterocolitis modified by Walsh-Kliegman

\begin{tabular}{|c|c|c|c|c|}
\hline Stage & Systemic signs & Abdominal signs & Radiologic signs & Treatment \\
\hline $\begin{array}{l}\text { IA } \\
\text { Suspected }\end{array}$ & $\begin{array}{l}\text { Temperature instability, } \\
\text { apnea, bradycardia. }\end{array}$ & $\begin{array}{l}\text { Elevated gastric residuals, } \\
\text { mild abdominal distension, } \\
\text { occult blood in stool. }\end{array}$ & Normal or mild ileus. & $\begin{array}{c}\text { NPO } \\
\text { antibiotics } \times 3 \text { days. }\end{array}$ \\
\hline $\begin{array}{l}\text { IB } \\
\text { Suspected }\end{array}$ & Same as above. & Bright red blood from rectum. & Normal or mild ileus. & Same as IA. \\
\hline $\begin{array}{l}\text { IIA } \\
\text { Mild NEC }\end{array}$ & Same as stage I & $\begin{array}{l}\text { Marked abdominal distension, } \\
\text { absent bowel sounds, } \\
\text { abundant blood in stool. }\end{array}$ & $\begin{array}{c}\text { Ileus, dilation of } \\
\text { intestinal loops, } \\
\text { pneumatosis intestinalis. }\end{array}$ & $\begin{array}{l}\text { NPO, antibiotics } \\
\text { x 7-10 days. }\end{array}$ \\
\hline $\begin{array}{l}\text { IIB } \\
\text { Moderate }\end{array}$ & $\begin{array}{l}\text { Mild acidosis. } \\
\text { Thrombocytopenia. }\end{array}$ & $\begin{array}{l}\text { Abdominal wall edema. } \\
\text { Palpable and tender mass. }\end{array}$ & $\begin{array}{l}\text { Extensive pneumatosis, } \\
\text { portal vein gas. } \\
\text { Early ascites. }\end{array}$ & $\begin{array}{l}\text { NPO, antibiotics } \\
\quad \text { x } 14 \text { days. }\end{array}$ \\
\hline $\begin{array}{l}\text { IIIA } \\
\text { Severe } \\
\text { meta } \\
\text { hy }\end{array}$ & $\begin{array}{l}\text { Apnea, } \\
\text { mechanical ventilation, } \\
\text { abolic or respiratory acidosis, } \\
\text { yypotension, oliguria, DIC. }\end{array}$ & $\begin{array}{l}\text { Increased abdominal wall edema } \\
\text { with erythema } \\
\text { and induration. }\end{array}$ & $\begin{array}{l}\text { Prominent ascites. } \\
\text { Fixed intestinal loop, } \\
\text { without free air. }\end{array}$ & $\begin{array}{l}\text { NPO, antibiotics } x 14 \text { days, } \\
\text { fluids, inotropic agents, } \\
\text { ventilation therapy, } \\
\text { paracentesis. }\end{array}$ \\
\hline $\begin{array}{l}\text { IIIB } \\
\text { Severe }\end{array}$ & $\begin{array}{c}\text { IIIA plus rapid } \\
\text { deterioration and shock. }\end{array}$ & $\begin{array}{l}\text { Severe abdominal distension, } \\
\text { absent bowel sounds. } \\
\text { Abdominal wall edema, } \\
\text { bruising, induration. }\end{array}$ & $\begin{array}{l}\text { Subdiaphragmatic } \\
\text { free air. } \\
\text { Pneumoperitoneum. }\end{array}$ & Same as IIIA plus surgery. \\
\hline
\end{tabular}

NPO: nothing by mouth; NEC: necrotizing enterocolitis; DIC: disseminated intravascular coagulation. 
group from 2012 to 2014 and the intervention group from 2015 to 2017. Newborn infants who had not received the probiotic adequately or did not fulfill the above-mentioned criteria were excluded.

The nursing staff directly administered probiotics orally to EP infants, with a daily dose of 5 drops of LRP (containing 108 colony forming units [CFUs]), starting between the $3^{\text {rd }}$ and $7^{\text {th }}$ day of life until reaching 36 weeks of corrected gestational age.

NEC was defined as the inflammation of the small or large intestine with different degrees of severity according to Bell's criteria modified by Walsh and Kliegman (Table 1). Probiotics: live microorganisms contributing to the development of the normal gut flora. Prebiotics: plant or starch fibers that provide nutrients. Gut microbiota: group of bacteria living harmoniously in the gut without causing any damage which provide benefits for the body. Microbiome: the genetic composition of all the microbiota present in the different systems of the body.

After obtaining the approval of the Ethics Committee, patients' demographic and clinical information was collected retrospectively since 2019 by reviewing the medical records and discharge notes from both groups. The authorization of the Scientific Ethics Committee of the South Araucanía Health Service was received on February $11^{\text {th }}, 2019$.

No informed consent was requested given that this was a routine treatment. The admission informed consent was related to the hospitalization authorization and necessary treatment measures. It was not possible to request it either at the time of data collection because patients were no longer present. In addition, patients' privacy was maintained at all times. This situation was outlined to the hospital's Ethics Committee and the Regional Ethics Committee.

Data were analyzed using the Stata software; Fisher's exact test was used to compare percentages, and the unequal variances t-test, for averages. The level of significance was set at $5 \%$.

\section{RESULTS}

The study sample of EP infants is presented in the flow chart (Figure 1). The average weight of the probiotic group was $1318.28 \mathrm{~g}$ and that of the control group, $1213.93 \mathrm{~g}$. The average gestational age of the probiotic group was 29.71 weeks and

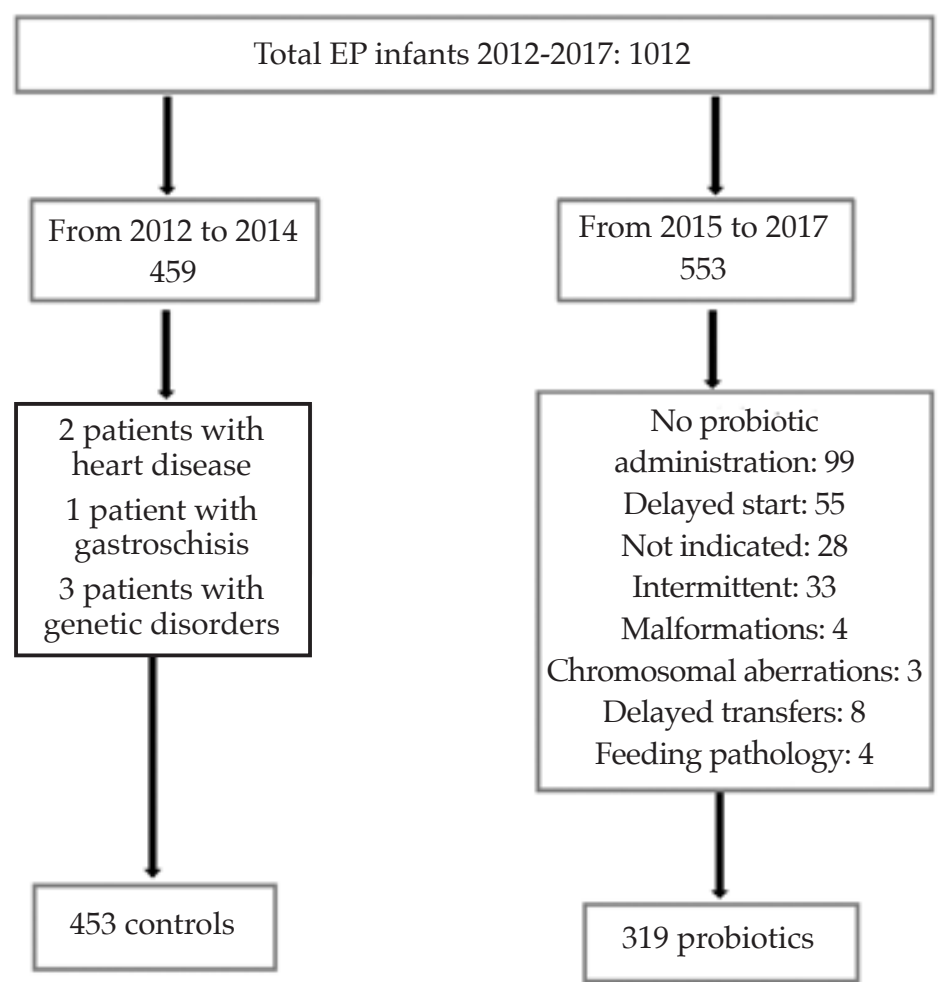

EP: extremely preterm. 
that of the control group, 28.99 weeks (standard deviation [SD]: 2.49). Significant associations were observed with birth weight, gestational age, Apgar score at 1 and 5 minutes, and umbilical venous catheter insertion. However, no significant differences were found in relation to sex, premature rupture of membranes, umbilical arterial catheter insertion, and red blood cell (RBC) transfusion (Table 2).

Out of the 319 patients receiving probiotics, $11(3.45 \%)$ had some degree of NEC: stage IB was observed in 7 out of the 11 patients; stage II, in 2 patients; and stage III, also in 2 patients.
Regarding the type of treatment, 2 of the 11 neonates required surgical treatment, which accounted for $18 \%$ of all NEC patients in this group, and there were no deaths.

In the control group, 17 of the 453 patients had NEC $(3.75 \%)$, with the following distribution: stage IB was observed in 2 patients; stage II, in 6; and stage III, in 9. Surgery was required in 11 of the 17 patients, and 8 of them died of enterocolitis or due to a related consequence, which accounted for $47 \%$ of neonates with NEC (Figure 2).

When grouping the patients with the most severe stages, according to the modified Bell's

TABLE 2. Characteristics of both groups

\begin{tabular}{|c|c|c|c|}
\hline Group & $\begin{array}{l}\text { Probiotic: } \mathbf{n}=\mathbf{3 1 9} \\
(2015-2017 \text { period })\end{array}$ & $\begin{array}{l}\text { Control: } \mathbf{n}=\mathbf{4 5 3} \\
(2012-2014 \text { period })\end{array}$ & $p$ \\
\hline Average weight in grams & 1318.28 (SD: 320.12) & 1213.93 (SD: 358.50$)$ & $<0.0001^{*}$ \\
\hline Average gestational age at birth & 29.71 weeks (SD: 2.15) & 28.99 weeks (SD: 2.49 ) & $<0.0001^{*}$ \\
\hline Average Apgar score at $1 \mathrm{~min}$ & 6.97 points (SD: 2.21$)$ & 6.52 points (SD: 2.19$)$ & $0.0122^{*}$ \\
\hline Average Apgar score at $5 \mathrm{~min}$ & 8.64 points (SD: 1.28 ) & 8.21 points (SD: 1.70$)$ & $0.0001^{*}$ \\
\hline Venous catheter & $273 / 319(85.58 \%)$ & $346 / 453(76.38 \%)$ & $0.002^{* *}$ \\
\hline Sex & F/M 159/160 (49.84/50.16\%) & F/M 205/248 (45.25/54.75\%) & $0.214^{\star *}$ \\
\hline Premature rupture of membranes & $47 / 319(14.73 \%)$ & $92 / 453(20.31 \%)$ & $0.057^{* *}$ \\
\hline Arterial catheter & $92 / 319(28.84 \%)$ & $130 / 453(28.70 \%)$ & $1^{* *}$ \\
\hline Red blood cell transfusion & $184 / 319(57.68 \%)$ & $271 / 453(59.82 \%)$ & $0.553^{* *}$ \\
\hline
\end{tabular}

* Unequal variances test; ** Fisher's exact test.

SD: standard deviation.

FIGURE 2. Percentage of enterocolitis stages: I (mild), II (moderate), III (severe)

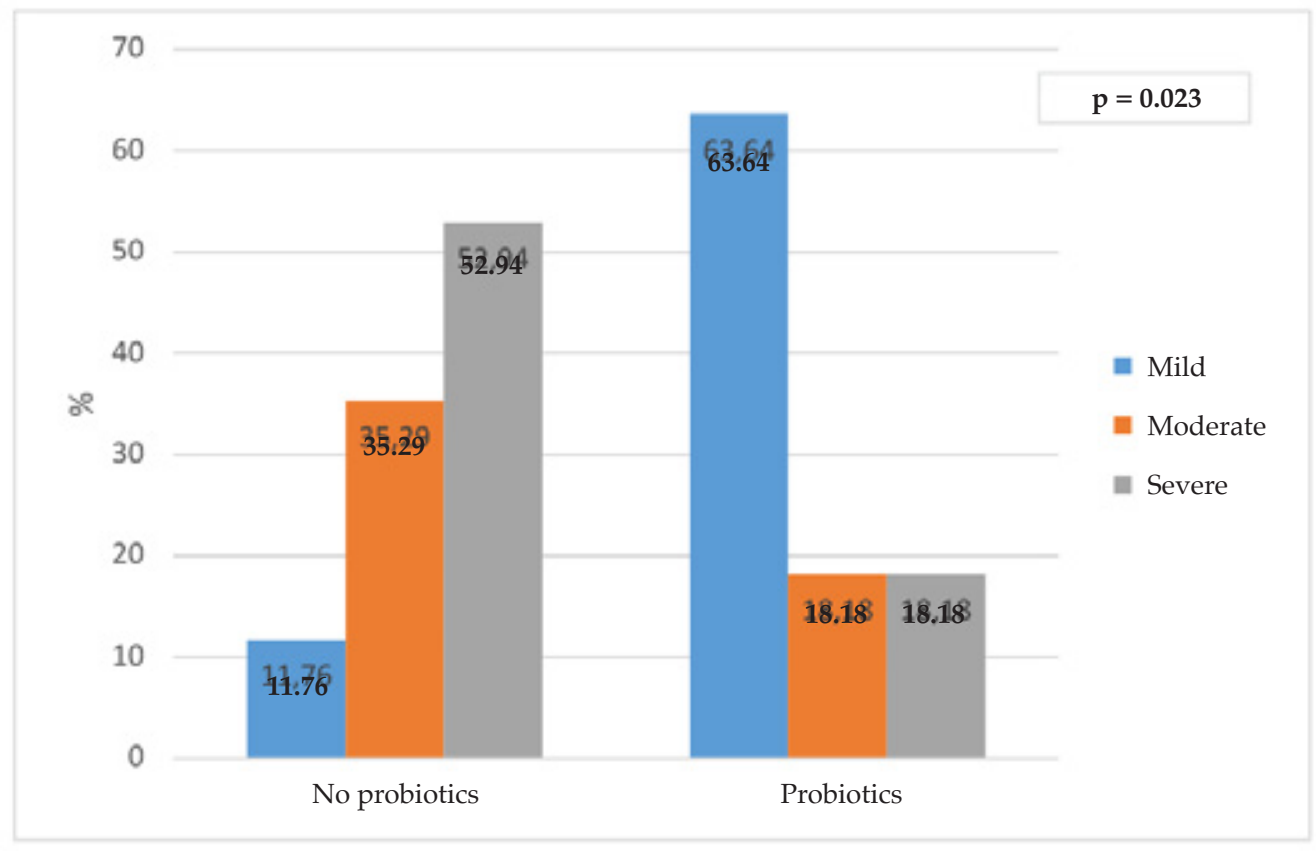


criteria, in the intervention group, stages II and III combined accounted for 4 out of 11 patients (relative risk [RR]: 0.41). In contrast, in the control group, these stages accounted for 15 of the $17 \mathrm{EP}$ infants with NEC.

The antibiotic treatment scheme of EP infants with NEC was similar in both groups (ampicillinamikacin for stage I, and metronidazole was also added for stages II and III). In addition, treatment protocols were implemented to avoid excessive use. Feeding was done with breast milk or with formula and breast milk combined, and very occasionally, exclusively with formula.

\section{DISCUSSION}

In this study, the incidence of NEC was low in both groups, severe enterocolitis was less common in the probiotic group, which also had a lower requirement for surgery and a lower fatality rate. Patients with severe NEC were more common in the control group.

Our preventive treatment is supported by its routine use in some European countries (in addition to Canada and Australia) to prevent NEC in EP infants. ${ }^{10-14}$ Denmark has clinical guidelines for the use of probiotics in preterm newborn infants. ${ }^{15}$ A systematic review of observational studies has confirmed the benefits of the enteral administration of probiotics in preterm neonates. ${ }^{16}$

In 2008, the administration of a probiotic (Lactobacillus casei rhamnosus, Lcr35) was introduced as a standard of care for all EP infants at Dijon University Hospital, in France. A 3-year retrospective study showed the association between probiotic administration and a reduced risk of severe NEC and late mortality, without adverse effects in the treated population when compared to a historical cohort. ${ }^{17}$

The scientific medical literature continues to report the results of its studies from different strategic perspectives: the administration of multiple strains versus a single strain, ${ }^{18}$ the administration of probiotics on their own, the administration of probiotics together with fructooligosaccharides, or pentoxifylline, or arginine and lactoferrin, as food additives. These studies have been conducted through a network meta-analysis. ${ }^{19}$ Recently, the use of para-probiotics has been proposed as the next frontier, which are inactivated probiotics or their components that would produce a beneficial response in the newborn's body. ${ }^{20}$

Regarding Lactobacillus reuteri, a probiotic first isolated from a Peruvian woman's breast milk in 1991, its colonization of the gastrointestinal tract and survival in the digestive tract have been demonstrated. It produces reuterin, a potent, broad-spectrum antimicrobial compound, with studies proving its beneficial effects on the preterm infant's digestive tract by reducing gastrointestinal infections, sepsis, and hospital stay, ${ }^{21-23}$ and in the prevention of NEC, a study conducted by Athalye-Jape in preterm neonates indicates a level-II evidence. ${ }^{24}$ In addition, Lactobacillus reuteri produces regulatory changes in the $\mathrm{T}$ cells of the intestine and mesenteric lymph nodes, and maintains intestinal homeostasis, by reestablishing regulatory T-cell deficiency in patients with NEC. It allows to control intestinal inflammation and improves food tolerance, according to experimental studies of NEC induced in rats. ${ }^{25,26}$

The incidence of enterocolitis observed in both groups was lower than that mentioned in some research studies from the bibliography. ${ }^{1,2}$

There were no differences between the intervention group and the control group, in contrast to some studies where an important reduction of NEC incidence was observed with the use of probiotics. ${ }^{27}$

The low incidence of NEC in our division, when compared to other publications, may be partly explained by the early oral administration of colostrum to all admitted neonates, and particularly to EP infants. It may also be explained by the fact that mothers can freely access their babies $24 / 7$, and by the pumping of milk next to the incubator, which reduces the emotional stress of the mother and the baby, and facilitates feeding with breast milk.

In relation to the severity of enterocolitis, stages II and III combined were found to be lower in the treated group than in the control group. The trend observed in this group was a reduction of higher stages ( 4 of 11 versus 15 of 17 when combining Bell's stages II and III), as opposed to what happened with controls, which increased with severity. This was consistent with what has been described in the bibliography for the same probiotic. $^{27}$

The reduction of surgery requirement was directly related to the lower severity observed in the treated group. Surgical intervention was the last level of treatment and entailed the risk of associated complications, i.e., adhesions, stenosis, partial obstructions, complete obstructions, fistulas or the dreaded short bowel syndrome. 
In spite of being rarely mentioned in the bibliography, in our study, the surgical aspect was consistent with previous publications. ${ }^{27}$

When analyzing the fatality rate in both groups, differences were observed between them, given that, in this review, no deaths associated with or resulting from enterocolitis were recorded in the intervention group, in contrast to the $47 \%$ fatality rate of NEC found in the control group. These results differed from some publications where no differences were observed when using the same probiotic. ${ }^{28,29}$

The strengths of this study are that it is the first using this probiotic in Chile and it has shown favorable results for its use in neonates.

The weaknesses of this study include its retrospective cohort nature; not having included data on maternal or fetal pathologies causing preterm birth; and not having analyzed other outcome measures, such as days of hospitalization, days at the intensive care unit (ICU), days of mechanical ventilation, days of parenteral nutrition, and post-surgery complications.

\section{CONCLUSIONS}

Our results support that, although the incidence of NEC was not reduced by administering a single daily dose of LRP to EP infants since the $3^{\text {rd }}$ day of life until 36 weeks of corrected gestational age, there were less cases of severe NEC. There was also a lower requirement for surgical treatment and there were no deaths, compared to a control group from the previous 3 years.

\section{REFERENCES}

1. Robertson C, Savva GM, Clapuci R, Jones J, et al. Incidence of necrotising enterocolitis before and after introducing routine prophylactic Lactobacillus and Bifidobacterium probiotics. Arch Dis Child Fetal Neonatal Ed. 2020;105(4):3806.

2. Horbar JH, Carpenter JH, Badger GJ, Kenny MJ, et al. Mortality and neonatal morbidity among infants 501 to 1500 grams from 2000 to 2009. Pediatrics. 2012; 129(6):101926.

3. Gewolb IH, Schwalbe RS, Taciak VL, Harrison TS, et al. Stool microflora in extremely low birthweight infants. Arch Dis Child Fetal Neonatal Ed. 1999; 80(3):F167-73.

4. Goldmann DA, Leclair J, Macone A. Bacterial colonization of neonates admitted to an intensive care environment. $J$ Pediatrics. 1978; 93(2):288-93.

5. Nolan LS, Rimer JM, Good M. The role of human milk oligosaccharides and probiotics on the neonatal microbiome and risk of necrotizing enterocolitis: a narrative review. Nutrients. 2020; 12(10):3052.

6. Alfaleh K, Anabrees J, Bassler D, Al-Kharfi T. Probiotics for prevention of necrotizing enterocolitis in preterm infants. Cochrane Database Syst Rev. 2011; (3):CD005496.
7. Morgan RL, Preidis GA, Kashyap PC, Weizman AV, et al. Probiotics reduce mortality and morbidity in preterm, low-birth-weight infants: a systematic review and network meta-analysis of randomized trials. Gastroenterology. 2020; 159(2):467-80.

8. Braegger C, Chmielewska A, Decsi T, Kolacek S, et al. Supplementation of infant formula with probiotics and/ or prebiotics: a systematic review and comment by the ESPGHAN committee on nutrition. J Pediatr Gastroenterol Nutr. 2011; 52(2):238-50.

9. Shelby RD, Raab R, Besner GE, McElroy SJ. Hope on the horizon: promising novel therapies for necrotizing enterocolitis. Pediatr Res. 2020; 88(Suppl 1):30-4.

10. Deshpande G, Rao S, Patole S. Probiotics in neonatal intensive care-Back to the future. Aust NZJObstet Gynaecol. 2015; 55(3):210-7.

11. Härtel C, Pagel J, Rupp J, Bendiks M, et al. Prophylactic use of Lactobacillus acidophilus / Bifidobacterium infantis probiotics and outcome in very low birth weight infants. J Pediatr. 2014; 165(2)285-9.

12. Janvier A, Malo J, Barrington KJ. Cohort study of probiotics in a North American neonatal intensive care unit. J Pediatr. 2014; 164(5):980-5.

13. Uberos J, Aguilera-Rodríguez E, Jerez-Calero A, MolinaOya $\mathrm{M}$, et al. Probiotics to prevent necrotising enterocolitis and nosocomial infection in very low birth weight preterm infants. Br J Nutr. 2017; 117(7):994-1000.

14. Patole SK, Rao SC, Keil AD, Nathan EA, et al. Benefits of Bifidobacterium breve M-16V supplementation in preterm neonates-A retrospective cohort study. PLoS One. 2016; 11(3):e0150775.

15. Danish National Guideline. Probiotics for preterm GA 30 weeks [in Danish]. [Accessed on: November 2011]. Available at: http: / / www.rh-vejledninger.dk/C1256FF60 028FE3A/0 /FADF649DDFCAFF2FC12576A B0030868D? OpenDocument\&Highlight_2.

16. Olsen R, Greisen G, Schroder M, Brok J. Prophylactic probiotic for preterm infants: a systematic review and meta-analysis of observational studies. Neonatology. 2016; 109(2):105-12.

17. Bonsante F, Iacobelli S, Gouyon JB. Routine probiotic use in very preterm infants: Retrospective comparison of two cohorts. Am J Perinatol. 2013; 30(1):41-6.

18. Chang HY, Chen JH, Chang JH, Lin HC, et al. Multiple strains probiotics appear to be the most effective probiotics in the prevention of necrotizing enterocolitis and mortality: An update meta-analysis. PLoS One. 2017; 12(2):e0171579.

19. Yu W, Sui W, Mu L, Yi W, et al. Preventing necrotizing enterocolitis by food additives in neonates. A network meta-analysis revealing the efficacy and safety. Medicine (Baltimore). 2017; 96(21):e6652.

20. Deshpande G, Athalye-Jape G, Patole S. Para-probiotics for preterm neonates, the next frontier. Nutrients. 2018; 10(7):871.

21. Rojas MA, Lozano JM, Rojas MX, Rodriguez VA, et al. Prophylactic probiotics to prevent death and nosocomial infection in preterm infants. Pediatrics. 2012; 130(5):e111320.

22. Romeo MG, Romeo DM, Trovato L, Oliveri S, et al. Role of probiotics in the prevention of the enteric colonization by Candida in preterm newborns: incidence of late-onset sepsis and neurological outcome. J Perinatol. 2011;31(1):639.

23. Indrio F, Riezzo G, Raimondi F, Bisceglia M, et al. The effects of probiotics on feeding tolerance, bowel habits, and gastrointestinal motility in preterm newborns. J Pediatr. 2008; 152:801-6.

24. Athalye-Jape G, Rao S, Patole S. Lactobacillus Reuteri 
DSM 17938 as a probiotic for Preterm Neonates: A StrainSpecific Systematic Review. JPEN J Parenter Enteral Nutr. 2016; 40(6):783-94.

25. Liu Y, Fatheree N, Mangalat N, Rhoads JM. Lactobacillus reuteristrains reduce incidence and severity of experimental necrotizing enterocolitis via modulation of TLR4 and NF$\mathrm{kB}$ signaling in the intestine. Am J Physiol Gastrointest Liver Physiol. 2012; 302(6):G608-17.

26. He B, Hoang TK, Wang T, Ferris M, et al. Resetting microbiota by Lactobacillus reuteri inhibits T reg deficiencyinduced autoimmunity via adenosine A2A receptors. J Exp Med. 2017; 214(1):107-23

27. Hunter C, Dimaguila MA, Gal P, Wimmer J Jr, et al. Effect of routine probiotic, Lactobacillus reuteri DSM 17938 , use on rates of necrotizing enterocolitis in neonates with birthweight < 1000 grams: a sequential analysis. BMC Pediatr. 2012; 12:142.

28. Hernández-Henríquez N, Rosas-Sumano AB, MonzoyVentre MA, Galicia-Flores L. Lactobacillus reuteri DSM 17938 en la prevención de enterocolitis necrosante en recién nacidos prematuros. Estudio piloto de eficacia y seguridad. Rev Mex Pediatr. 2015; 81(2):37-43.

29. OncelMY, Sari FN, ArayiciS, Guzoglu N, et al. Lactobacillus Reuteri for the prevention of necrotising enterocolitis in very low birthweight infants: a randomised controlled trial. Arch Dis Child Fetal Neonatal Ed. 2014; 99(2):F110-5. 